\title{
Extrato de casca de café, óleo essencial de tomilho e acibenzolar-S-metil no manejo da cercosporiose-do-cafeeiro
}

\author{
Ricardo Borges Pereira ${ }^{(1)}$, Eduardo Alves(1), Pedro Martins Ribeiro Júnior ${ }^{(1)}$, Mário Lúcio Vilela de Resende(1), \\ Gilvaine Ciavareli Lucas ${ }^{(1)}$ e Josimar Batista Ferreira ${ }^{(2)}$
}

(1)Universidade Federal de Lavras, Departamento de Fitopatologia, Caixa Postal 3037, CEP 37200-000 Lavras, MG. E-mail: ricardoborgespereira@yahoo.com.br, ealves@ufla.br, ribeirojuniorpm@yahoo.com.br, mlucio@ufla.br, gilciavareli@yahoo.com.br. (2)Universidade Federal do Acre, Campus Floresta, Centro de Ciências Biológicas e da Natureza, Estrada Canela Fina, s/nº, CEP 69980-000 Cruzeiro do Sul, AC. E-mail: josimarferreira@gmail.com

Resumo - O objetivo deste trabalho foi avaliar o efeito de concentrações de extrato de casca de café, óleo essencial de tomilho e acibenzolar-S-metil na germinação, no crescimento micelial e no desenvolvimento in vivo de Cercospora coffeicola, além de caracterizar a eficiência deles como indutores de resistência, e determinar a atividade da enzima peroxidase e o acúmulo de lignina nos tecidos de cafeeiro. $\mathrm{O}$ extrato de casca de café não afetou a germinação, entretanto, inibiu o crescimento micelial proporcionalmente ao aumento das concentrações. O óleo essencial de tomilho inibiu a germinação e o crescimento micelial com o aumento das concentrações. $\mathrm{O}$ extrato de casca de café e o acibenzolar-S-metil não afetaram a germinação nem o desenvolvimento dos tubos germinativos, diferentemente do óleo essencial de tomilho. Mudas tratadas com acibenzolar-S-metil, extrato de casca de café e óleo essencial de tomilho, apresentaram picos de atividade da peroxidase aos 2 e 11, 7 e 11 e, 2 e 9 dias após a aplicação dos tratamentos, respectivamente. Os tratamentos não diferiram quanto à concentração de lignina. Extrato de casca de café e acibenzolar-S-metil induziram resistência em mudas de cafeeiro contra C. coffeicola e o óleo essencial de tomilho apresentou efeito tóxico ao patógeno.

Termos para indexação: Cercospora coffeicola, Coffea arabica, indução de resistência, microscopia eletrônica de varredura.

\section{Coffee berry husk extract, thyme essential oil and acibenzolar-S-methyl in the control of brown eye spot of coffee tree}

\begin{abstract}
The objective of this work was to assess the effect of the coffee berry husk extract, thyme essential oil and acibenzolar-S-methyl on the germination and micelial growth and on in vivo development of Cercospora coffeicola, and to characterize their efficiency as resistance inducers in coffee plants, and to determine the peroxidase activity and lignin accumulation in tissues of coffee tree. The coffee berry husk extract presented no toxic effect on germination; however, it inhibited the mycelial growth proportionally to the increase of the concentrations. The thyme essential oil inhibited the germination and the mycelial growth with the increase of concentrations. Both coffee berry husk extract and acibenzolar-S-methyl neither affected the germination nor the development of germinative tubes, differently of thyme essential oil. Seedlings treated with acibenzolarS-methyl, coffee berry husk extract and thyme essential oil presented peaks of peroxidase activity at $2^{\text {nd }}$ and $11^{\text {th }}, 7^{\text {th }}$ and $11^{\text {th }}$ and, $2^{\text {nd }}$ and $9^{\text {th }}$ days after treatment, respectively. The treatments did not differ in lignin content. Coffee berry husk extract and acibenzolar-S-methyl induced resistance in coffee seedlings against C. coffeicola, and thyme essential oil presented toxic effect on the pathogen.
\end{abstract}

Index terms: Cercospora coffeicola, Coffea arabica, resistance induction, scanning electron microscopy.

\section{Introdução}

A cercosporiose do cafeeiro (Coffea arabica L.), causada por Cercospora coffeicola Berk \& Cooke é uma das principais doenças das lavouras cafeeiras e pode causar prejuízos diretos e indiretos aos produtores. Essa doença ocupa posição de destaque na cultura do café, pois pode afetar mudas em formação e lavouras adultas, e os sintomas podem ser observados em folhas e frutos (Zambolim et al., 2005). O patógeno normalmente causa intensa desfolha da planta, o que reduz a produção. Ataques intensos do patógeno no 
campo ocorrem, principalmente, em regiões altas e com solos pouco férteis, e pode causar perdas de até $30 \%$ na produção (Pozza et al., 2000).

Freqüentemente, para o controle convencional da cercosporiose, têm sido utilizados fungicidas protetores e sistêmicos. No entanto, a resistência induzida, aplicada com sucesso recentemente em outros patossistemas, tem sido considerada promissora no controle de C. coffeicola. Contudo, o uso eficiente dessa estratégia depende da disponibilidade de eficientes eliciadores (Gullino et al., 2000). Trabalhos têm sido conduzidos com o intuito de testar novos compostos eliciadores capazes de ativar, de forma eficiente, os mecanismos de defesa em plantas.

Óleos essenciais apresentaram eficiência no controle de doenças, tanto por sua ação fungitóxica, que inibe o crescimento micelial e a germinação de esporos, quanto pela presença de compostos eliciadores. Medice et al. (2007) observaram redução na severidade da ferrugem-da-soja (Glycine max (L.) Merr.), causada por Phakopsora pachyrhizi, de 35 a $62 \%$, em plantas tratadas com óleos essenciais de eucalipto citriodora (Corymbia citriodora Hill \& Johnson), tomilho (Thymus vulgaris L.), citronela (Cymbopogon nardus) e nim (Azadirachta indica A. Juss.) sete dias antes da inoculação.

Extratos vegetais também têm sido eficientes no controle de doenças. Como exemplo, o extrato de casca de café, no controle da mancha-de-phoma (Barguil et al., 2005), da cercosporiose (Santos et al., 2007; Amaral, 2005) e da ferrugem-docafeeiro (Santos et al., 2007). Além do uso do extrato de ramos de lobeira (Solanum lycocarpum St. Hil.), infectados por Crinipellis perniciosa (Stahel) Singer, no controle da mancha-bacteriana em tomateiro (Cavalcanti et al., 2006), do extrato de folhas de café severamente afetadas pela ferrugem (Hemileia vastatrix Berk. \& Br.), no controle da mancha-de-phoma em cafeeiro (Barguil et al., 2005) e, dos extratos de casca de maracujá (Passiflora edulis Sims), no controle da murcha-de-verticílio em cacaueiro (Pereira et al., 2008).

O objetivo deste trabalho foi avaliar o efeito do extrato de casca de café (ECC), óleo essencial de tomilho (OET) e acibenzolar-S-metil (ASM) na germinação, no crescimento micelial e desenvolvimento de Cercospora coffeicola, em folhas de mudas de cafeeiro, por meio de microscopia eletrônica de varredura (MEV); avaliar a eficiência do ECC, OET e ASM como indutores de resistência no controle da cercosporiose-do-cafeeiro e, avaliar a atividade da enzima peroxidase e o acúmulo de lignina em folhas de mudas de cafeeiros.

\section{Material e Métodos}

Os experimentos foram realizados no primeiro semestre de 2006, na Universidade Federal de Lavras, Lavras, MG.

Para a obtenção do ECC, $100 \mathrm{~g}$ de cascas de frutos de café (pericarpo) foram inicialmente secadas em estufa a $60^{\circ} \mathrm{C}$ por 48 horas, e moídas e ressuspensas em $500 \mathrm{~mL}$ de água destilada, e conduzida a extração a quente por 2 horas, sob refluxo. Em seguida, a suspensão foi filtrada a vácuo e teve seu volume completado para $500 \mathrm{~mL}$ com água destilada, adaptado de Barguil et al. (2005). O extrato obtido (ECC $200 \mathrm{~g} \mathrm{~L}^{-1}$ ) foi armazenado em freezer a $-20^{\circ} \mathrm{C}$ e utilizado para as demais diluições. O OET foi adquirido da Brasil Portrait (2008).

Para a obtenção do inóculo de C. coffeicola, folhas naturalmente infectadas no campo foram coletadas e submetidas à câmara úmida por três dias. Em seguida, realizou-se a raspagem dos conídios produzidos com pincel de cerdas macias umedecidas em água destilada. A suspensão obtida foi filtrada em gaze e ajustada em hemocitômetro à concentração de $1,5 \times 10^{4}$ conídios $\mathrm{mL}^{-1}$, concentração essa utilizada em todos os experimentos.

A fim de verificar o efeito do ECC e do OET, na germinação de conídios e no crescimento micelial de C. coffeicola, foram realizados dois experimentos in vitro. Os tratamentos consistiram de ECC nas concentrações de $0,10,50,100,150$ e $200 \mathrm{~g} \mathrm{~L}^{-1}$, OET nas concentrações de $0,125,250,500,1.000$ e $2.000 \mathrm{ppm}$ e, acibenzolar-S-metil (ASM) $0,2 \mathrm{~g} \mathrm{~L}^{-1}$, utilizado como padrão de indução de resistência.

Para o teste de germinação, foram utilizadas placas de Petri de $6 \mathrm{~cm}$ de diâmetro, com meio ágar-água (AA) $2 \%$, no qual foram adicionados $1 \mathrm{~mL}$ dos tratamentos, nas concentrações preestabelecidas, e $1 \mathrm{~mL}$ da suspensão de conídios. Em seguida, as placas foram acondicionadas em BOD a $25^{\circ} \mathrm{C}$, por 24 horas, e fotoperíodo de 12 horas de luz. O experimento foi realizado em delineamento inteiramente casualizado, 
com duas placas para cada tratamento, cada uma dividida em quatro quadrantes, tendo sido avaliados 30 conídios por quadrante, num total de oito repetições. Após a incubação, a germinação foi paralisada pela adição de duas gotas de solução de lactoglicerol. Em seguida, foi avaliada a percentagem de germinação dos conídios em microscópio de luz.

Para avaliar o crescimento micelial, foram utilizadas placas de Petri de $9 \mathrm{~cm}$ de diâmetro com meio BDA $2 \%$. Os tratamentos foram adicionados ao meio antes que este fosse vertido nas placas e após a queda da temperatura para $40^{\circ} \mathrm{C}$, de modo que as diluições finais atingissem as preestabelecidas pelo ensaio. Nos tratamentos com OET, foi adicionado propilenoglicol 2\% (surfactante) ao meio BDA. No centro de cada placa, foi adicionado um disco de meio com $6 \mathrm{~mm}$ de diâmetro com micélio de C. coffeicola. Em seguida, as placas foram acondicionadas em $\mathrm{BOD}$ a $25^{\circ} \mathrm{C}$ e fotoperíodo de 12 horas, tendo permanecido nessa condição até o final das avaliações. O experimento foi realizado em delineamento inteiramente casualizado, com oito repetições e cada parcela constituída por uma placa de Petri. Foram realizadas avaliações a cada quatro dias, desde a inoculação até que o micélio do tratamento testemunha ocupasse toda a superfície do meio. Em seguida, foi calculado o índice de crescimento micelial (ICM), por adaptação da fórmula proposta por Maguire (1962).

As mudas de cafeeiro utilizadas nos experimentos com MEV e na caracterização bioquímica foram obtidas pela semeadura da cultivar Mundo Novo $379 / 19$, em bandejas de isopor (72 células), com substrato comercial Plantmax HT. As plantas foram irrigadas diariamente com solução nutritiva de Hoagland \& Arnon (1950), até a formação do terceiro par de folhas verdadeiras. Elas foram mantidas em casa de vegetação $\left(25 \pm 3^{\circ} \mathrm{C}\right)$ durante todo o período experimental.

Para realizar o estudo com a MEV, mudas de cafeeiro foram pulverizadas com ECC $150 \mathrm{~g} \mathrm{~L}^{-1}$, OET 500 ppm, ASM 0,2 $\mathrm{g} \mathrm{L}^{-1}$ e água destilada, até o ponto de escorrimento, utilizando-se um pulverizador manual. Sete dias depois, quatro folhas do terceiro par de cada tratamento foram coletadas, lavadas em água destilada e acomodadas em bandejas de plástico, previamente desinfestadas e preparadas, conforme Ferreira (2006). Na superfície abaxial de cada folha, foram desenhados quatro círculos de $1 \mathrm{~cm}$ de diâmetro. No centro de cada círculo, foram depositados $30 \mu \mathrm{L}$ da suspensão de conídios de C. coffeicola. As bandejas com as folhas foram cobertas com plástico transparente e mantidas em câmara de crescimento a $24^{\circ} \mathrm{C}$ e fotoperíodo de 12 horas, até o final do experimento. As coletas das amostras, para observação em MEV, foram realizadas 4, 8, 16 e 48 horas após a inoculação, por meio de cortes circulares ( $5 \mathrm{~mm}$ de diâmetro), feitos com bisturi, dentro de cada círculo previamente demarcado. O preparo e a observação das amostras foram realizados conforme Bossola \& Russell (1998).

A fim de avaliar a eficácia do extrato do ECC e do OET, no controle da cercosporiose em plantas de cafeeiro, mudas cultivadas conforme metodologia descrita anteriormente foram transplantadas para vasos de $4 \mathrm{~L}$ com substrato composto por terra, areia e esterco bovino $(2: 1: 1)$ e, mantidas em casa de vegetação $\left(25 \pm 3^{\circ} \mathrm{C}\right)$ durante todo o período experimental. Plantas com dez pares de folhas foram pulverizadas com: ECC - nas concentrações de 10, $50,100,150$ e $200 \mathrm{~g} \mathrm{~L}^{-1}$; OET - nas concentrações de $125,250,500,1.000$ e $2.000 \mathrm{ppm}$; ASM - 0,2 $\mathrm{g} \mathrm{L}^{-1}$, e água destilada, até o ponto de escorrimento, utilizando-se pulverizador manual. Sete dias depois da aplicação, as plantas receberam inóculos via pulverização com uma suspensão de conídios e, em seguida, foram submetidas à câmara úmida por 14 horas. Adotou-se o delineamento de blocos casualizados, com quatro repetições e cada parcela composta por seis plantas. Foram realizadas cinco avaliações a cada 14 dias. Em seguida, calculou-se a área abaixo da curva de progresso do número de lesões da cercosporiose (AACPL), de acordo com Shaner \& Finney (1977).

Para determinar a atividade da enzima peroxidase e o acúmulo de lignina nos tecidos do cafeeiro, foram selecionados os tratamentos mais eficientes no controle da doença, em casa de vegetação, e o tratamento-padrão com ASM. Foram avaliados: ECC $150 \mathrm{~g} \mathrm{~L}^{-1}$; ECC $150 \mathrm{~g} \mathrm{~L} \mathrm{~L}^{-1}$, seguido de inoculação; OET 500 ppm; OET 500 ppm, seguido de inoculação; ASM 0,2 $\mathrm{g} \mathrm{L}^{-1}$; ASM 0,2 $\mathrm{g} \mathrm{L}^{-1}$, seguido de inoculação; e testemunha com inoculação. Plantas com três pares de folhas verdadeiras foram pulverizadas até o ponto de escorrimento e, depois 
de sete dias, foram submetidas à inoculação conforme descrito anteriormente. O delineamento foi o de blocos casualizados com três repetições e parcela composta por três plantas.

Todas as folhas das plantas utilizadas para quantificar proteínas totais e a atividade de peroxidase foram coletadas aos 2, 4, 7, 8, 9, 11 e 14 dias após a aplicação dos tratamentos. Por ocasião da última amostragem, foram coletadas folhas para a quantificação de lignina. Imediatamente após cada coleta, as folhas foram congeladas em nitrogênio líquido e, armazenadas a $-80^{\circ} \mathrm{C}$, até o momento da maceração. Na quantificação de proteínas totais e da atividade da peroxidase, $3 \mathrm{~g}$ de folhas das plantas de cada tratamento foram macerados em almofariz onde se adicionou tampão acetato de sódio (cloreto de sódio $0,5 \mathrm{M}$ e ácido cítrico 0,4\%) $50 \mathrm{mM}$, pH 5,2, por três min em banho de gelo. Em seguida, a mistura foi filtrada em pano de trama fina, e a suspensão foi centrifugada a $12.000 \mathrm{~g}$ por $20 \mathrm{~min}, \mathrm{a} 4^{\circ} \mathrm{C}$. O sobrenadante foi coletado, para ser utilizado como fonte enzimática, e mantido a $-80^{\circ} \mathrm{C}$ até o momento das análises enzimáticas.

As proteínas solúveis contidas nos extratos foram aferidas com base no ensaio de Bradford (1976), com uso de um padrão de albumina sérica bovina (BSA). A atividade da peroxidase foi determinada de acordo com o método de Kar \& Mishra (1976), tendo-se utilizado como substrato o guaiacol, na presença de peróxido de hidrogênio. Os resultados da atividade enzimática foram expressos em miligrama de proteína por minuto. A quantificação de lignina foi determinada de acordo com o método de Monties (1989), por meio do ensaio com ácido tioglicólico, e calculada com base em uma curva-padrão, constituída com diferentes concentrações de lignina-padrão (alkali, 2-hidroxipropil éter). Os resultados foram expressos em miligrama de lignina por grama de matéria fresca.

Os dados foram submetidos à análise de variância, e as comparações de médias realizadas pelo teste de Scott-Knott, a $5 \%$ de probabilidade, para os fatores qualitativos, e análises de regressão para fatores quantitativos. Os dados de percentagens de germinação foram transformados em arc sen $\mathrm{x}^{0,5}$.

\section{Resultados e Discussão}

Maior germinação de conídios foi observada nos tratamentos constituídos de ECC, em relação à testemunha (dose 0) (Figura $1 \mathrm{~A})$. A germinação apresentou comportamento quadrático na medida em que as concentrações do extrato se elevaram, com máxima germinação na concentração de $186 \mathrm{~g} \mathrm{~mL}^{-1}$. O OET reduziu a germinação de conídios de forma linear com o aumento das concentrações (Figura 1 B), com uma $\mathrm{DL}_{50}$ - concentração capaz de inibir a germinação ou provocar a morte de pelo menos $50 \%$ dos conídios - estimada em 10.341 ppm.

O ECC e o OET promoveram reduções no índice de crescimento micelial (ICM) (Figura $1 \mathrm{C}$ e D). O ICM apresentou um comportamento linear, com o aumento das concentrações do extrato, e um comportamento quadrático, com o aumento das concentrações do óleo. A $\mathrm{DL}_{50}$ do ECC e do OET foram estimadas em $410 \mathrm{~g} \mathrm{~L}^{-1}$ e $621 \mathrm{ppm}$, respectivamente.

Os conídios iniciaram a germinação quatro horas após a inoculação em todos os tratamentos, com exceção do tratamento constituído de OET, no qual a germinação foi pouco evidenciada nas observações ao MEV (Figura 2). Nos tratamentos em que as plantas foram tratadas com ECC, os conídios de C. coffeicola originaram tubos germinativos mais desenvolvidos e em maior número, micélio mais desenvolvido e crescimento micelial superior aos demais tratamentos, 8, 16 e 48 horas após a inoculação, respectivamente. Neste caso, grande quantidade do extrato ainda encontrava-se aderido à superfície foliar. No entanto, nos tratamentos em que as plantas foram tratadas com OET, os conídios do fungo apresentaram baixa geminação, crescimento reduzido e extravasamento celular. O ASM não apresentou qualquer alteração na germinação e no desenvolvimento micelial de C. coffeicola na superfície de folhas de cafeeiro.

Barguil et al. (2005) e Amaral (2005), ao testar o ECC no crescimento micelial de Phoma costaricensis e C. coffeicola, não observaram efeito tóxico do extrato sobre esses patógenos, no entanto, os autores utilizaram somente a concentração de $100 \mathrm{~g} \mathrm{~L}^{-1}$, possivelmente insuficiente para a inibi-los, como observado neste trabalho. Segundo Pandey et al. (2000), a casca de café possui grande quantidade de carboidratos, proteínas, taninos e vários compostos fenólicos, encontrados principalmente na polpa. Possivelmente, a germinação dos conídios foi estimulada pela grande quantidade de açúcares presentes na casca, e o crescimento micelial foi inibido pela presença de taninos, que, segundo Santos \& Mello (1999), desempenham importante 
papel na inativação de enzimas e impede o crescimento de alguns microrganismos.

Diversos trabalhos relatam o efeito antimicrobiano de óleos essenciais no desenvolvimento in vitro de alguns patógenos. Souza et al. (2004) observaram total inibição do crescimento micelial de Rhizopus sp.,Penicillium spp., Eurotium repens e Aspergillus niger, nas concentrações 500, 1.000, 1.500 e 2.000 ppm, respectivamente. Zambonelli et al. (1996) observaram, por meio da $\mathrm{MEV}$, que o óleo de tomilho a $800 \mathrm{ppm}$ diminuiu o crescimento micelial e promoveu a degeneração de hifas e o extravasamento celular de Colletotrichum lindemuthianum e Pythium ultimum. Medice (2007), ao utilizar o mesmo óleo a 3.000 ppm, observou que urediniósporos de P. pachyrhizi encontravam-se murchos e inviáveis para germinação. Segundo Zambonelli et al. (2004), a inibição da germinação de conídios e do crescimento micelial se deve à presença de compostos tóxicos, como timol e carvacrol presentes no óleo, que apresentam propriedades bactericidas e fungicidas (Pinto et al., 2001). É importante observar que os resultados obtidos neste trabalho com o uso da MEV corroboram os resultados observados in vitro. Segundo Kuć (2001), geralmente os indutores de resistência no senso estrito não atuam diretamente sobre o patógeno, no entanto, no senso amplo, podem induzir a resistência na planta e também afetar o patógeno diretamente.

Em casa de vegetação, tanto o ECC quanto o OET reduziram a área abaixo da curva de progresso do número de lesões da cercosporiose (AACPL) (Figura 3). Todavia, o ECC proporcionou maior redução. A AACPL, referente aos tratamentos constituídos de ECC, apresentou comportamento quadrático e reduziu a incidência da doença com o aumento das concentrações, com maior redução (35\% em relação à testemunha) na concentração de $116 \mathrm{~g} \mathrm{~L}^{-1}$, a partir da qual constatouse aumento da incidência da doença (Figura 3 A). De maneira semelhante, a AACPL dos tratamentos constituídos de OET apresentou comportamento quadrático, e os tratamentos reduziram a incidência da doença em 16,1\%, em relação à testemunha, na concentração de 1.149 ppm (Figura 3 B). O tratamentopadrão ASM reduziu a AACPL em 36,5\%, em relação à testemunha.
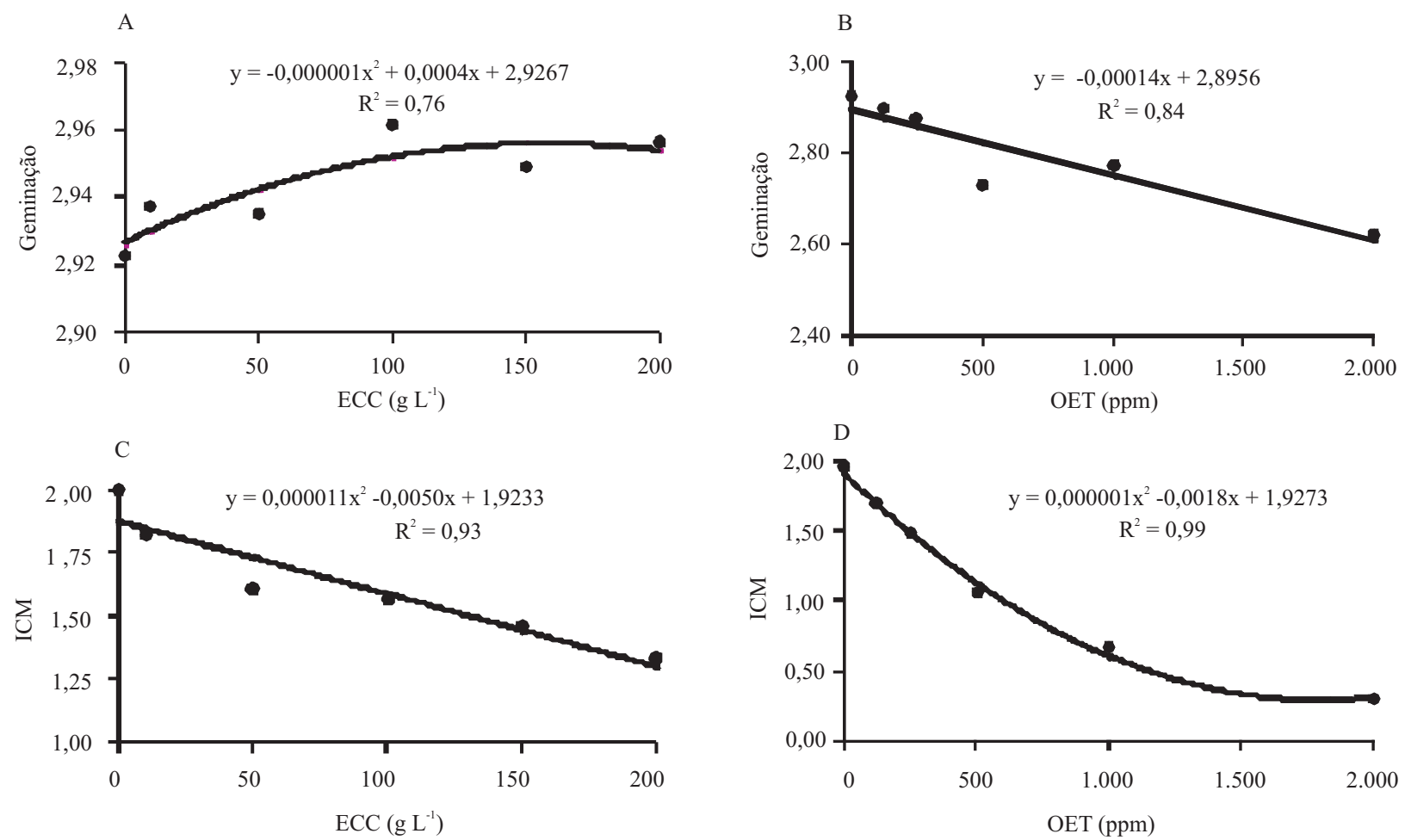

Figura 1. Efeito de diferentes concentrações do extrato de casca de café (ECC) e do óleo essencial de tomilho (OET) na germinação de conídios e no índice de crescimento micelial (ICM) de Cercospora coffeicola. Para análise, os dados de germinação foram transformados em $\operatorname{arc} \operatorname{sen} \mathrm{x}^{0,5}$. 

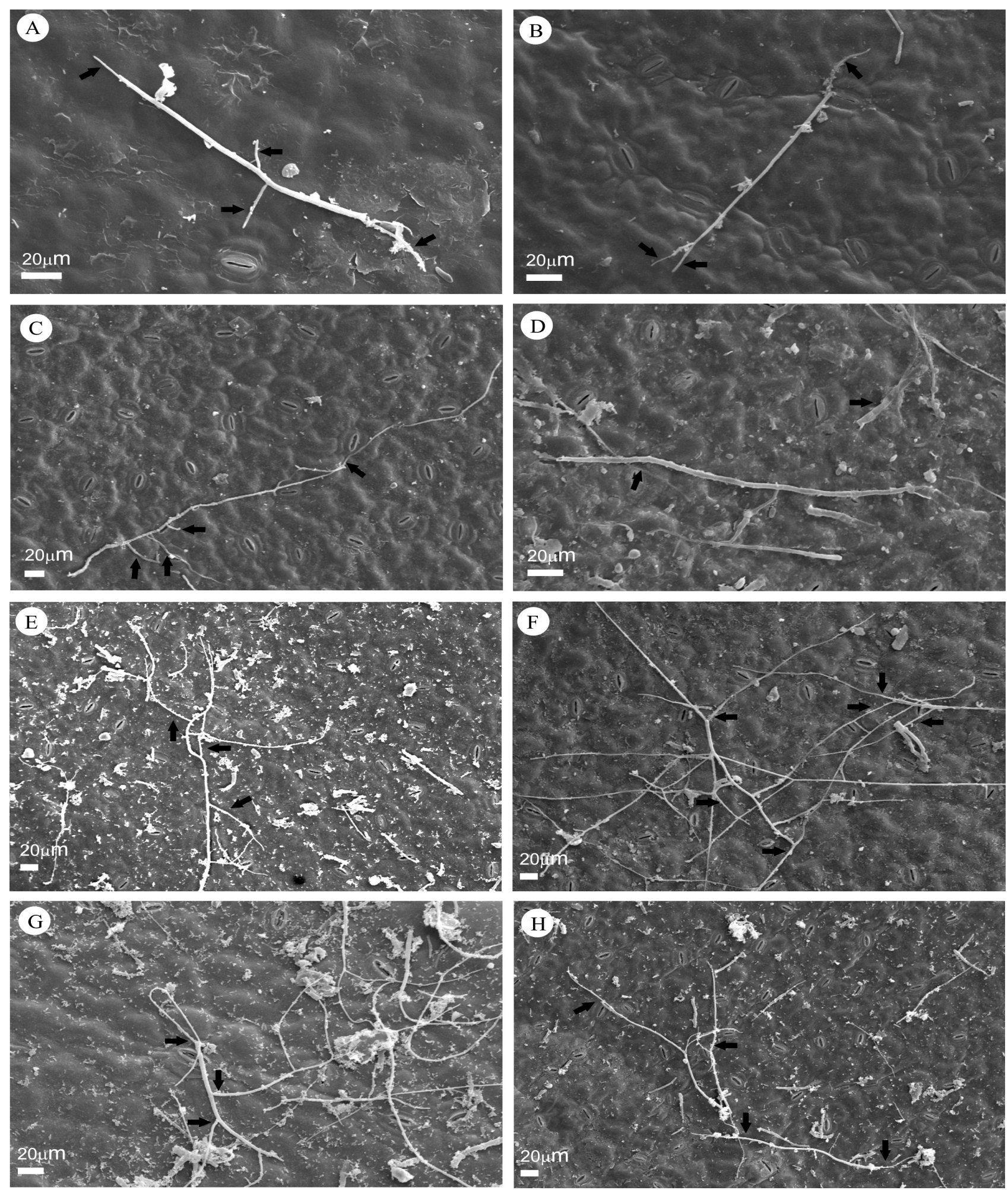

Figura 2. Eletromicrografia de varredura de folhas de cafeeiro submetidas à inoculação (A a D) e 48 horas após inoculação $(\mathrm{E} \mathrm{a} \mathrm{H})$ de Cercospora coffeicola. A e E: plantas tratadas com acibenzolar-S-metil a 0,2 mg mL $\mathrm{mL}^{-1}$; B e F: com extrato de casca de café a $150 \mathrm{~g} \mathrm{~L}^{-1}$; C e G: testemunha somente com inoculação de conídios na fase inicial da germinação (setas); D e H: plantas tratadas com óleo essencial de tomilho a 500 ppm, apresentando germinação reduzida (setas). 
Alguns autores já confirmaram o efeito do ECC no controle da cercosporiose. Amaral (2005) e Santos et al. (2007) obtiveram reduções de até $40 \%$ na AACPI em mudas de cafeeiro, em casa de vegetação, e 34\% em lavoura orgânica no campo, respectivamente. Barguil et al. (2005) observaram que o extrato afetou negativamente o tamanho e o número de lesões de $P$. costaricensis. O controle obtido por meio do extrato possivelmente se deveu aos compostos fenólicos presentes em sua fração solúvel, que, segundo Pascholati \& Leite (1994), podem constituirse em componentes de defesa da planta contra fatores externos. No caso do óleo de tomilho, o controle de C. coffeicola se deu possivelmente pela presença de compostos como timol, cravacrol fenóis, quinonas, saponinas, flavanóides e terpenóides (Silva Júnior \& Vizzoto, 1996).

Com relação à atividade da enzima peroxidase, plantas pulverizadas com ASM apresentaram picos de atividade superiores às plantas do tratamento testemunha 2 e 11 dias após a pulverização (DAP) (Figura 4 A). Plantas tratadas com ASM e com inoculação apresentaram picos de atividade $8 \mathrm{DAP}$ um pequeno pico $14 \mathrm{DAP}$, ambos superiores à testemunha com inoculação. Plantas tratadas exclusivamente com ECC apresentaram picos de atividade superiores à testemunha 7 e 11 DAP, e picos inferiores aos das plantas tratadas com ECC e com inoculação aos 11 DAP (Figura 4 B). Esse comportamento é um indicativo de que a inoculação, por si, pode promover aumento na atividade da enzima. Plantas tratadas apenas com OET apresentaram picos de atividade da enzima 2 e 9 DAP, e plantas pulverizadas com o OET e com inoculação apresentaram pico 8 DAP (Figura $4 \mathrm{C}$ ). As concentrações de lignina não diferiram entre si pelo teste de Scott-Knott, a 5\% de probabilidade. No entanto, plantas tratadas com ASM, ECC e OET apresentaram concentrações de ligninas superiores às do tratamento testemunha (Figura $4 \mathrm{D}$ ).

Em relação à atividade da enzima peroxidase e a concentração de lignina, resultados similares foram obtidos por Amaral (2005), que observou picos de atividade da enzima peroxidase $15 \mathrm{DAP}$, em mudas de cafeeiro tratadas com ASM e 20 DAP, em plantas tratadas comECC.Cavalcanti etal.(2006) observaram picos dessa enzima em tomateiro tratado com ASM e com inoculação de Xanthomonas vesicatoria 9 e 12 DAP. Segundo Mazzafera et al. (1989), plantas com inoculação geralmente apresentam picos de atividade de peroxidase superiores às sem inoculação. A relação positiva entre a atividade da peroxidase e a resistência de plantas a doenças tem sido relatada em diversos trabalhos, e o aumento da atividade de peroxidase durante o desenvolvimento da doença tem sido correlacionado à expressão de resistência em diferentes patossistemas (Silva et al., 2007). Santos et al. (2007) observaram concentrações superiores de lignina em plantas tratadas com ECC,
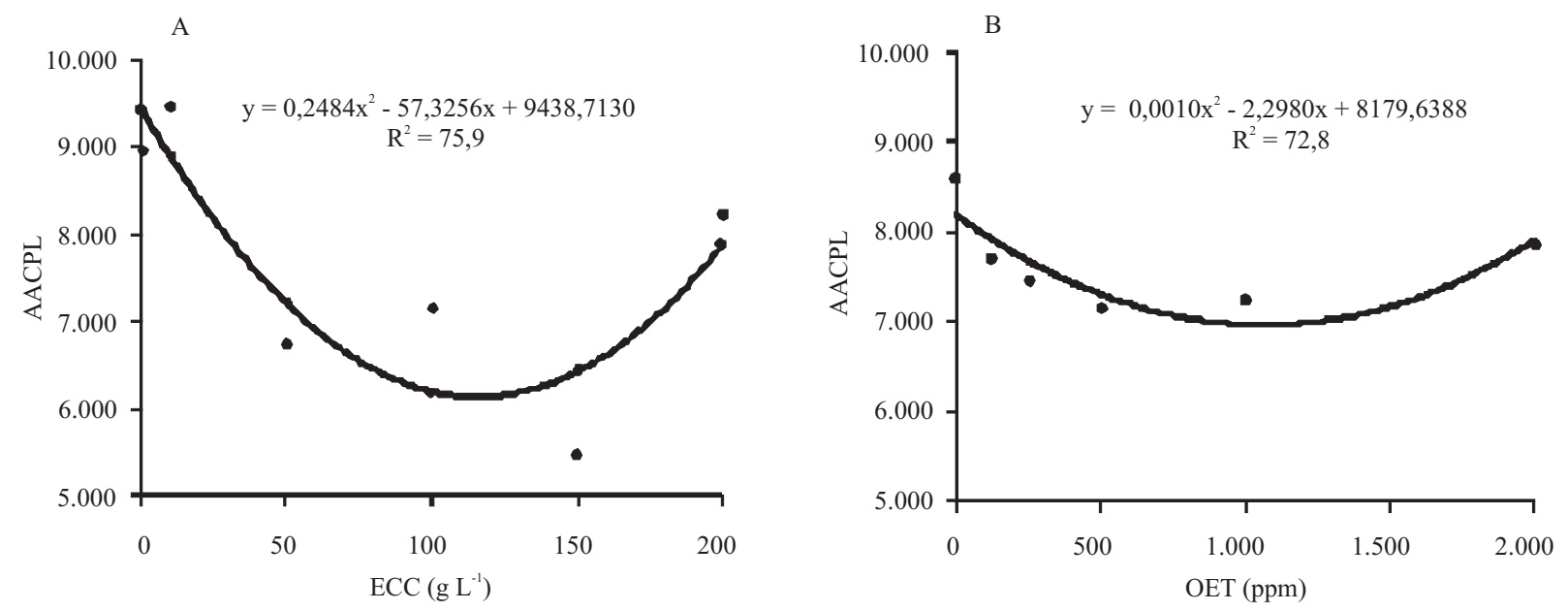

Figura 3. Área abaixo da curva de progresso do número de lesões da cercosporiose (AACPL) 70 dias após a inoculação de Cercospora coffeicola em mudas de cafeeiro cultivar Mundo Novo, e tratadas com extrato de casca de café (ECC) e óleo essencial de tomilho (OET). 

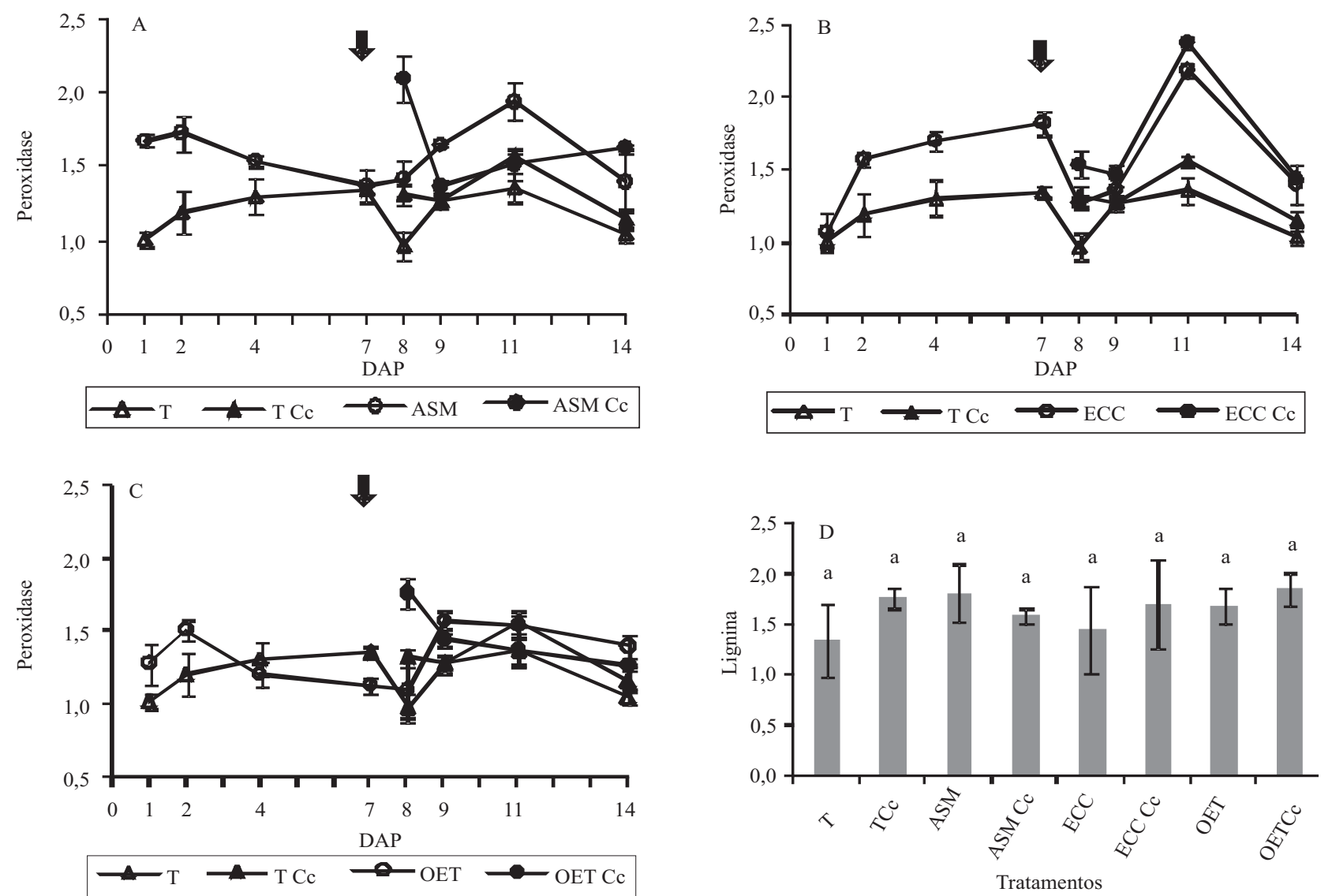

Figura 4. Atividade da enzima peroxidase (UA por mg de proteína por min) em diferentes dias após a pulverização (DAP) (A, B e C). Concentração de lignina ácido-solúvel total (mg por g de matéria fresca) 14 dias após pulverização (D) em folhas de cafeeiro, cultivar Mundo Novo 379/19. T, testemunha; ASM, acibenzolar-S-metil a 0,2 g L L $^{-1}$; ECC, extrato de casca de café a $150 \mathrm{~g} \mathrm{~L}^{-1}$; OET, óleo de tomilho a 500 ppm. Inoculação de Cercospora coffeicola $(\mathrm{Cc})$ (setas em A, B e C). As barras indicam o desvio-padrão. Letras iguais nas colunas indicam tratamentos que não diferiram entre si pelo teste Scott-Knott, a 5\% de probabilidade.

em campo, 126 DAP. Já Amaral (2005) observou aumento na concentração de lignina 20 DAP, em plantas tratadas com o mesmo extrato, porém elas não diferiram em relação à testemunha. Diferenças nas concentrações de lignina não foram observadas neste trabalho, provavelmente, em razão do intervalo de tempo insuficiente entre o tratamento das mudas e as coletas realizadas, o que também foi observado por Amaral (2005).

Pode-se sugerir que o controle da cercosporiose com OET se deu, principalmente, pelo seu efeito direto sobre o patógeno, e menos pela indução de resistência. Por outro lado, o ECC não apresentou efeito direto sobre o patógeno, mas provocou aumento na atividade da peroxidase. Assim o nível de controle da doença obtido com o uso desse extrato é resultante da indução de resistência em mudas de cafeeiro. Entretanto, para comprovação, as atividades de outras enzimas ligadas à defesa precisam ser determinadas. Postula-se que $o$ controle da cercosporiose do cafeeiro, em mudas no viveiro, é uma das possibilidades mais promissoras de utilização do ECC e do OET.

\section{Conclusões}

1. Concentrações crescentes do extrato de casca de café apresentam efeito tóxico in vitro ao crescimento micelial de Cercospora coffeicola, porém não inibem a germinação dos conídios.

2. Concentrações crescentes de óleo essencial de tomilho in vitro diminuem a germinação de conídios e o crescimento micelial de C. coffeicola. 
3. O extrato de casca de café não prejudica os estágios iniciais de desenvolvimento de C. coffeicola em folhas de cafeeiro; diferentemente do óleo essencial de tomilho, que é tóxico aos conídios e retarda o desenvolvimento micelial.

4. Acibenzolar-S-metil a $0,2 \mathrm{~g} \mathrm{~L} \mathrm{~L}^{-1}$, extrato de casca de café a $150 \mathrm{~g} \mathrm{~L}^{-1}$ e óleo essencial de tomilho a $500 \mathrm{ppm}$ conferem proteção parcial em plantas de cafeeiro desafiadas por C. coffeicola.

5. Acibenzolar-S-metil, extrato de casca de café e óleo essencial de tomilho elevam a atividade da enzima peroxidase em folhas de cafeeiro, mas não aumentam a concentração de lignina no tempo avaliado.

\section{Agradecimentos}

À Coordenação de Aperfeiçoamento de Pessoal de Nível Superior e à Fundação de Amparo à Pesquisa do Estado de Minas Gerais, pelo apoio financeiro.

\section{Referências}

AMARAL, D.R. Indução de resistência em cafeeiro contra Cercospora coffeicola por eliciadores abióticos e extratos vegetais. 2005. 96p. Dissertação (Mestrado) - Universidade Federal de Lavras, Lavras.

BARGUIL, B.M.; RESENDE, M.L.V.; RESENDE, R.S.; BESERRA JÚNIOR, J.E.A.; SALGADO, S.M.L. Effect of extracts from citric biomass, rusted coffee leaves and coffee berry husks on Phoma costarricencis of coffee plants. Fitopatologia Brasileira, v.30, p.535-537, 2005

BOSSOLA, J.J.; RUSSELL, L.D. Electron microscopy. Boston: Jones and Bartlett Publishers, 1998. 670p.

BRADFORD, M.M. A rapid and sensitive method for the quantitation of microgram quantities of protein utilizing principle of protein-dye binding. Analytical Biochemistry, v.72, p.248-254, 1976.

BRASIL PORTRAIT. Óleos essenciais. 2008. Disponível em: $<$ http://www.brasilportrait.com.br>. Acesso em: 24 maio 2008.

CAVALCANTI, F.R.; RESENDE, M.L.V. de; PEREIRA, R.B.; COSTA, J.C. do B.; CARVALHO, C.P. da S. Atividade de quitinase e beta-1,3-glucanase após eliciação das defesas do tomateiro contra a mancha-bacteriana. Pesquisa Agropecuária Brasileira, v.41, p.1721-1730, 2006.

FERREIRA, J.B. Aspectos histopatológicos, epidemiologia e controle da mancha manteigosa em Coffea arabica L. 2006. 159p. Tese (Doutorado) - Universidade Federal de Lavras, Lavras.

GULLINO, L.M.; LEROUX, P.; SMITH, C.M. Uses and challenges of novels compounds for plant disease control. Crop Protection, v.19, p.1-11, 2000.

HOAGLAND, D.R.; ARNON, D.I. The water-culture method for growing plants without soil. Berkeley: University of California, 1950.34p.
KAR, M.E.; MISHRA, D. Catalase, peroxidase and polyphenoloxidase actives during rice leaf senescence. Plant Physiology, v.57, p.315-319, 1976.

KUĆ, J. Concepts and direction of induced systemic resistance in plants and its application. European Journal of Plant Pathology, v.107, p.7-12, 2001.

MAGUIRE, J.D. Speed of germination-aid in selection and evaluation for seedling emergence and vigor. Crop Science, v.2, p.176-177, 1962.

MAZZAFERA, P.; GONÇALVES, W.; FERNANDES, J.A.R. Fenóis, peroxidases e polifenoloxidases na resistência do cafeeiro a Meloidogyne incognita. Bragantia, v.48, p.131-142, 1989.

MEDICE, R . Produtos alternativos no manejo da ferrugem asiática (Phakopsora pachyrhizi) da soja. 2007. 102p. Dissertação (Mestrado) - Universidade Federal de Lavras, Lavras.

MEDICE, R.; ALVES, E.; ASSIS, R.T. de; MAGNO JÚNIOR, R.G.; LOPES, E.A. das G.L. Óleos essenciais no controle da ferrugem asiática da soja Phakopsora pachyrhizi Syd. \& P. Syd. Ciência e Agrotecnologia, v.31, p.83-90, 2007.

MONTIES, B. Lignins. In: DEY, P.M.; HARBORNE, J.B. Methods in plant biochemistry. New York: Academic Press, 1989. p.113-158.

PANDEY, A.; SOCCOL, C.R.; NIGAM, P.; BRAND, D.; MOHAN, R.; ROUSSOS, S. Biotechnological potential of coffee pulp and coffee husk for bioprocesses. Biochemical Engineering Journal, v.6, p.153-162, 2000 .

PASCHOLATI, S.F.; LEITE, B. Mecanismos bioquímicos de resistência às doenças. In: LUZ, W.C.; FERNANDES, J.M.; PRESTES, A.M.; PICININI, E.C. (Ed.). Revisão anual de patologia de plantas. Passo Fundo: Gráfica e Editora Padre Berthier dos Missionários da Sagrada Família, 1994. v.2. p.1-51.

PEREIRA, R.B.; RESENDA, M.L.V. de; RIBEIRO JÚNIOR, P.M.; AMARAL, D.R.; LUCAS, G.C.; CAVALCANTI, F.R. Ativação de defesa em cacaueiro contra a murcha-de-verticílio por extratos naturais e acibenzolar-S-metil. Pesquisa Agropecuária Brasileira, v.43, p.171-178, 2008.

PINTO, J.E.B.P.; LAMEIRA, O.L.; SANTIAGO, E.J.A. de; SILVA, F.G. Cultivo de plantas medicinais, aromáticas e condimentares. Lavras: Ufla/Faepe, 2001. 222p.

POZZA, A.A.A.; MARTINEZ, H.E.P.; POZZA, E.A.; CAIXETA, S.L; ZAMBOLIM, L. Intensidade da mancha de olho pardo em mudas de cafeeiro em função de doses de $\mathrm{N}$ e $\mathrm{K}$ em solução nutritiva. Summa Phytopathologica, v.26, p.29-33, 2000.

SANTOS, F.S.; SOUZA, P.E.; RESENDE, M.L.V.; POZZA, E.A.; MIRANDA, J.C.; RIBEIRO JÚNIOR, P.M.; MANEBRA, F.C. Efeito de extratos vegetais no progresso de doenças foliares do cafeeiro orgânico. Fitopatologia Brasileira, v.32, p.59-63, 2007.

SANTOS, S. da C.; MELLO, J.C.P. de. Taninos. In: SIMÕES, C.M.O.; SCHENKEL, E.P.; GOSMANN, G.; MELLO, J.C.P.; MENTZ, L.A.; PETROVICK, P.R. (Ed.). Farmacognosia: da planta ao medicamento. Porto Alegre: UFRGS, 1999. p.323-354. 
SHANER, G.; FINNEY, R.E. The effect of nitrogen fertilization on the expression of slow-midewing resistance in knox wheat. Phytopathology, v.67, p.1051-1056, 1977.

SILVA, R.F.; PASCHOLATI, S.F.; BEDENDO, I.P. Indução de resistência em tomateiro por extratos aquosos de Lentinula edodes e Agaricus blazei contra Ralstonia solanacearum. Fitopatologia Brasileira, v.32, p.189-196, 2007.

SILVA JÚNIOR, A.A.; VIZZOTTO, V.J. Plantas medicinais, aromáticas e fitoprotetoras. Agropecuária Catarinense, v.9, p.5-8, 1996.

SOUZA, S.M.C. de; PEREIRA, M.C.; ANGÉLICO, C.L.; PIMENTA, C.J. Avaliação de óleos essenciais de condimentos sobre o desenvolvimento micelial de fungos associados a produtos de panificação. Ciência e Agrotecnologia, v.28, p.685-690, 2004.
ZAMBOLIM, L.; VALE, F.X.R.; ZAMBOLIM, E.M. Doenças do cafeeiro(Coffea arabica e C. canephora). In: KIMATI, H.;AMORIM, L.; REZENDE, J.A.M.; BERGAMIM FILHO, A.; CAMARGO, L.E.A. (Ed.). Manual de fitopatologia: doenças de plantas cultivadas. 4.ed. São Paulo: Agronômica Ceres, 2005. v.2. p.165-180.

ZAMBONELLI, A.; D'AULERIO, A.Z.; BIANCHI, A.; ALBASIN, A. Effects of essential oils on phytopathogenic fungi in vitro. Journal of Phytopathology, v.144, p.491-494, 1996.

ZAMBONELLI, A.; D'AULERIO, A.Z.; SEVERI, A.; BENVENUTI, S.; MAGGI, L.; BIANCHI, A. Chemical composition and fungicidal activity of commercial essential oils of Thymus vulgaris L. Journal of Essential Oil Research, v.16, p.69-74, 2004.

Recebido em 3 de maio de 2008 e aprovado em 5 de setembro de 2008 